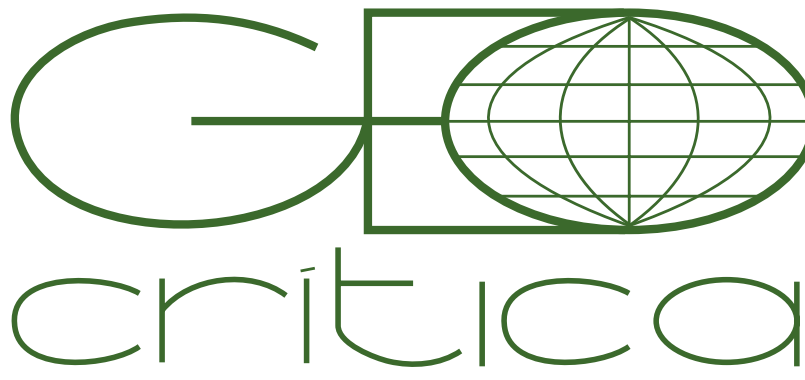

\section{Scripta Nova}

Revista Electrónica de Geografía y Ciencias Sociales Universitat de Barcelona

15 de septiembre de 2018

\title{
VECINOS RECUPERANDO LA MEMORIA: LA CÁRCEL DE CARABANCHEL
}

\author{
Sergio Claudio González García \\ Facultad de Ciencias Políticas y Sociología (UCM) \\ segonz01@ucm.es
}

Vecinos recuperando la memoria: la Cárcel de Carabanchel (Resumen)

La Cárcel de Carabanchel estuvo presente en el barrio madrileño durante más de sesenta años hasta su derribo. En torno a su futuro se formularon diversas demandas vecinales que permitieron la recuperación de su memoria y la apropiación del lugar. La movilización social se enfrentó no sólo a la eliminación de una memoria colectiva sino también a una determinada forma de producir el espacio. El estudio del conflicto por su futuro que se analiza en este artículo busca evidenciar la relación entre la forma en la que el espacio público es construido y las memorias colectivas.

Palabras clave: memoria, espacio, imaginarios, lugares de memoria, Carabanchel.

\section{Neighbours recovering memory: Carabanchel Prison (Abstract)}

Carabanchel Prison was in the neighbourhood for more than seventy years until it was demolished. Different demands about its future were proposed that allowed the recuperation of its memory and the appropriation of this place. Social mobilization faced not only to the elimination of collective memory but also to a specific way to produce the space. The analysis of the conflict about its future that is analysed in this article expects to demonstrate the relationship between the way that the public space is built and the collective memories.

Key words: memory, space, imaginaries, places of memory, Carabanchel. 
En los últimos años, los estudios de memoria han alcanzado un alto nivel de desarrollo académico y de reflexión intelectual. Desde diferentes disciplinas como la Historia, la Antropología, la Filosofía, la Historia del Arte y otras, la memoria colectiva y su importancia en los grupos humanos ha sido un objeto de estudio relevante. Algunas de estas investigaciones se han centrado en la idea de los 'lugares de memoria' -concepto vinculado con el historiador francés Pierre Nora ${ }^{1}$. De esta forma, la reflexión sobre la importancia de la memoria colectiva en los grupos sociales en base a las ideas de Maurice Halbwachs' ${ }^{2}$ y las contribuciones que han relacionado ésta con la idea de los lieux, han aumentado. Siguiendo esta línea, ahondando en aspectos que no han sido analizados en profundidad por la mayoría de estudios, en este artículo se pretende señalar que espacio y memoria tienen una conexión que va más allá de los monumentos y los memoriales. La preeminencia del tiempo sobre el espacio en los análisis de las Ciencias Sociales y la visión privilegiada en los estudios de memoria de ésta, como un elemento vinculado únicamente a la temporalidad, han supuesto que se deje de lado la idea de una memoria espacialmente constituida, por lo tanto, es necesario que los lugares sean entendidos en nuestras investigaciones como estructuras sociotemporales que escenifican la acumulación de significados y evidencian ese palimpsesto ${ }^{3}$. Profundizando en este enunciado, en las últimas dos décadas, nuevos estudios han considerado que si se entendía el pasado como una construcción social desde nuevas perspectivas, disciplinas como la Geografía podrían ofrecer una perspectiva espacial de esta construcción que permitiera analizar cómo marcas espaciales arrojaban luz sobre la forma en la que los discursos sobre el pasado eran articulados ${ }^{4}$.

Como se ha señalado en otras investigaciones, el análisis de lugares de memoria no ha conseguido explicar toda la profundidad de este proceso que debería ser analizado más allá de un marco estático, continuando la vía abierta por las teorías y las aproximaciones metodológicas del giro espacial en Ciencias Sociales ${ }^{5}$. Las aproximaciones empíricas de este hecho implican un conocimiento epistemológico de la importancia del espacio y la espacialidad en el análisis social ${ }^{6}$ que permite entender el proceso que vincula espacio y memoria más allá de una investigación histórica, artística o patrimonial. Esta importancia del espacio en el análisis social y de la memoria como objeto de estudio en diferentes disciplinas ha sido tomada en consideración por diferentes estudios en Geografía Humana que se han denominado 'Geografías de la memoria'7. La intención de este artículo es ahondar en la importancia de entender esta relación y también exponer, mediante un caso de estudio concreto, cómo está relación es conflictual y sujeta a una disputa constante entre distintas

\footnotetext{
1 Nora 1998.

2 Halbwachs 2004 [1925].

3 Till 2004.

4 Mitchell 2003; Foote 2007.

5 Cresswell 2004; Schmid 2008; Soja 2008.

6 Massey, 1993

7 Foote y Azaryahu, 2007.
} 
formas de producir el espacio que suponen el intento de imponer diferentes relatos del pasado.

Los elementos que van a permitir cohesionar esta reflexión sobre la memoria y el espacio para analizar la lucha por la Cárcel de Carabanchel van a ser las ideas de vivencia, concepción y percepción que provienen de la teorización unitaria del espacio que expuso Henri Lefebvre en sus planteamientos teóricos ${ }^{8}$. Esta visión unitaria que buscaba conocer el espacio social en su totalidad partía de entenderlo desde una relación trialéctica conflictiva y en disputa constante entre tres momentos interrelacionados, el espacio concebido, relacionado con la planificación y la proyección urbanística, el espacio percibido, que sería la forma más tangible por que la que se ocupa el espacio relacionado con la materialidad y, por último, el espacio vivido, el lugar de la resistencia anclada en la vida cotidiana donde residen los símbolos y significados que vinculan a una comunidad con su espacio9. Por ello, en este artículo, vamos a interactuar con estas categorías para explicar el conflicto por el uso de la cárcel y sus terrenos y, también, vamos a relacionar este conflicto con la disputa constante entre relatos del pasado oficiales y memorias colectivas subalternas. Entre lo que Enzo Traverso denomina 'memorias fuertes' y 'memorias débiles' ${ }^{10}$.

Así, con el análisis de la lucha por evitar el derribo de la Cárcel de Carabanchel, que se presenta en este artículo, se busca poner de manifiesto que la conexión entre espacio y memoria es parte de las relaciones de poder y las correlaciones de fuerzas, de tal manera que se entiende que el espacio, su uso y forma, no es un elemento neutral y dado a priori, sino construido en base a criterios, intencionalidad e ideología. Algo que se relaciona de manera dialéctica con las relaciones sociales. Por lo tanto, estas relaciones de poder convierten esta relación en un conflicto real que se expresa a través de demandas sociales, proyectos urbanos, espacios patrimoniales, rituales, conmemoraciones, homenajes y acciones colectivas. Por lo tanto, vamos a analizar cómo en el caso de la lucha por la recuperación y señalización de la Cárcel de Carabanchel se ponían en juego no sólo distintas ideas de lo que ésta significaba sino también relatos del pasado diferenciados, unos hegemónicos y otros de oposición, y concepciones distintas del espacio.

Para realizar este análisis, se va a proceder a relatar la evolución histórica de la prisión desde su creación hasta su derribo poniendo de manifiesto los elementos que permitieron configurar una relación entre cárcel y barrio. También se señalaran los elementos y acciones más significativas de la movilización social que reclamó la cárcel para su futuro uso y conservación. En el siguiente punto se procederá a cruzar estos elementos con los planteamientos teóricos lefebvrianos en relación a la producción del espacio para intentar configurar una nueva forma de aproximación a las luchas por los lugares de memoria que permita ver el conflicto por el espacio público en su relación con las disputas por la configuración de los relatos del pasado.

8 Lefebvre 2013 [1974].

9 Lefebvre 2013 [1974], p. 92-97.

10 Traverso 2007. 
Finalmente, se sintetizará lo expuesto en el artículo en una serie de conclusiones que permiten ver las relaciones concretas entre lo concebido, lo vivido y lo percibido con las memorias colectivas.

Todo este artículo es la culminación de una síntesis sobre el análisis realizado del trabajo de campo de la investigación llevado a cabo. Dicho trabajo se realizó a partir de un previo diseño metodológico triangular que buscaba combinar el análisis de las fuentes documentales, para conocer los discursos de los movimientos, la observación participante, para entender las formas de movilización y prácticas de los grupos, y las entrevistas semiestructuradas, como mejor forma de obtener información sobre los discursos, significados e ideas propias en los movimientos y de las personas implicadas en la movilización en torno a la recuperación de la Cárcel de Carabanchel. De esta manera, se procedió a realizar una revisión de manifiestos, revistas, documentación de asociaciones; también se acudió a los numerosos actos, concentraciones y manifestacioens posteriores al derribo de la prisión realizados por la Plataforma creada para las reclamaciones de la Cárcel; y, por último, se procedió a la realización de entrevistas semiestructuradas a informantes claves del proceso (vecinos, militantes, ex presos,...) a través de un método de key informant interviewing ${ }^{11}$.

\section{Por qué una cárcel en Carabanchel?}

No se puede entender el actual distrito de Carabanchel sin tener en consideración una serie de factores como son la anexión en los años 40 de los municipios independientes de Carabanchel Bajo y Alto ${ }^{12}$, el crecimiento urbano y demográfico de los años $60^{13}$ y la construcción al finalizar la Guerra Civil del centro penitenciario que quedaría estrechamente vinculado al mismo.

La vinculación del barrio con la Cárcel se produjo desde el momento de su construcción dado que se ponía de manifiesto el objetivo punitivo, redentor y de segregación social que tenían los proyectos urbanos del franquismo derivados de las corrientes organicistas, la experimentación urbana y la búsqueda del control social ${ }^{14}$. La idea de construcción del 'Gran Madrid' supuso el proyecto de anexión de los 'Carabancheles' que se ejecutaría en 1948 y que marcaría, desde ese momento, la configuración de la identidad y la memoria 'carabanchelera' relacionada con la idea de una existencia municipal previa que marcaría prácticas y reivindicaciones futuras.

La prisión fue construida por presos políticos que eran exhibidos, para aumentar el carácter punitivo y ejemplificante de la represión franquista, a través de las columnas de prisioneros que comunicaban la prisión provisional y las obras de la Cárcel, generando así una atmósfera de vigilancia, castigo y redención ${ }^{15}$. La Cárcel entró en funcionamiento en 1952 teniendo una población reclusa compuesta prin-

11 Blee y Taylor 2002, p.106.

12 Sánchez Molledo 2011, p.143-144.

13 Moreno Jiménez 1983, p.144-145.

14 Ortiz 2013, p. 53; Oviedo 2013, p. 67.

15 Oviedo 2013, p. 174. 
cipalmente por prisioneros políticos, prisioneros por delitos comunes durante la guerra y nuevos reclusos provenientes de la implantación del nuevo sistema penitenciario ${ }^{16}$. Pese a no ser nunca completamente una prisión dedicada en exclusiva al cautiverio de presos políticos, la presencia de los mismos y la centralidad de ésta dentro del sistema penitenciario franquista ${ }^{17}$ marcó la singularidad del lugar que se convirtió en un espacio de lucha debido a que existieron ciertas posibilidades de militancia en su interior que la clandestinidad no permitía.

El crecimiento urbano y demográfico de los años 60 supuso la incorporación del edificio a la trama urbana de la ciudad. La población de Carabanchel en esa época se multiplicó por cuatro con un aumento del número de viviendas de nueva planta, casi 38.000 en la década de los $60^{18}$, acompañado de un aumento de la construcción no regulada de vivienda con los consiguientes problemas de infraviviendas y hacinamiento ${ }^{19}$. En los años 70, esa articulación entre trama urbana y prisión se completaría de manera definitiva.

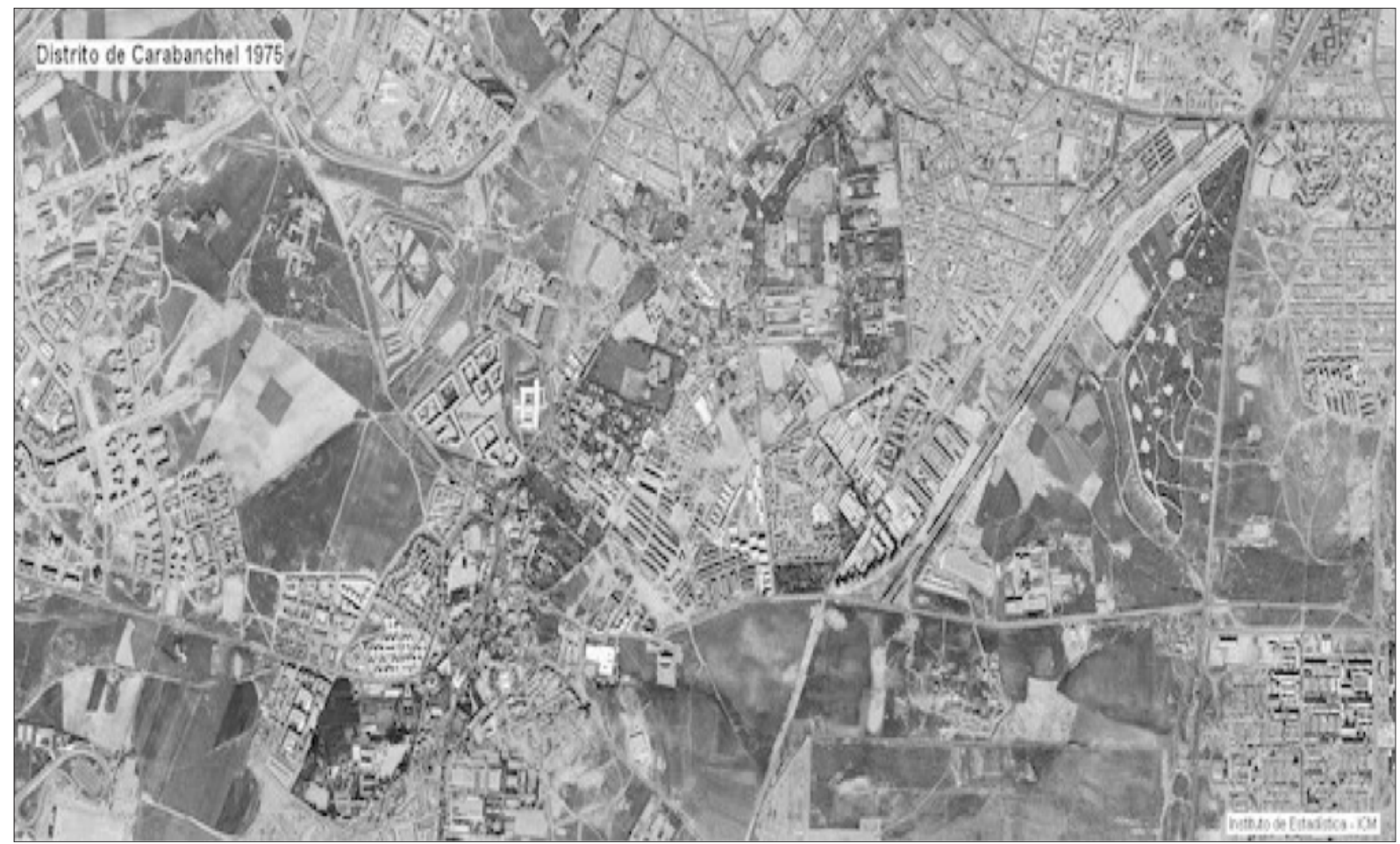

Figura 1: Foto aérea de Carabanchel (con la construcción radial de la Cárcel) en 1975.

Fuente: Instituto de Estadística de la Comunidad de Madrid. Nomenclátor Oficial y Callejero (http://www.madrid.org/nomecalles/).

La reorganización administrativa de los años 70 buscó poner una ordenación a este crecimiento urbano por medio de la división el territorio inicial del distrito en tres distritos de menor tamaño, Latina, Carabanchel y Usera. Esta modificación ur-

\footnotetext{
16 Ortiz 2013, p. 44.

17 Rodrigo 2003, p.108

18 Datos obtenidos del Sistema de Tabulación Online del Banco de Datos Territorial de la Comunidad de Madrid (http://www.madrid.org/bdt/inicio.icm).

19 Moreno Jiménez, 1983, p.182-185.
} 
bana y administrativa no alteró el imaginario geográfico ${ }^{20}$ que seguía vinculado a la identidad de pertenencia a Carabanchel Alto o Bajo tanto a nivel discursivo como a través de prácticas como fueron la denominación de las asociaciones de vecinos, el nombre de las paradas de la red de Metro e incluso las señales de tráfico.

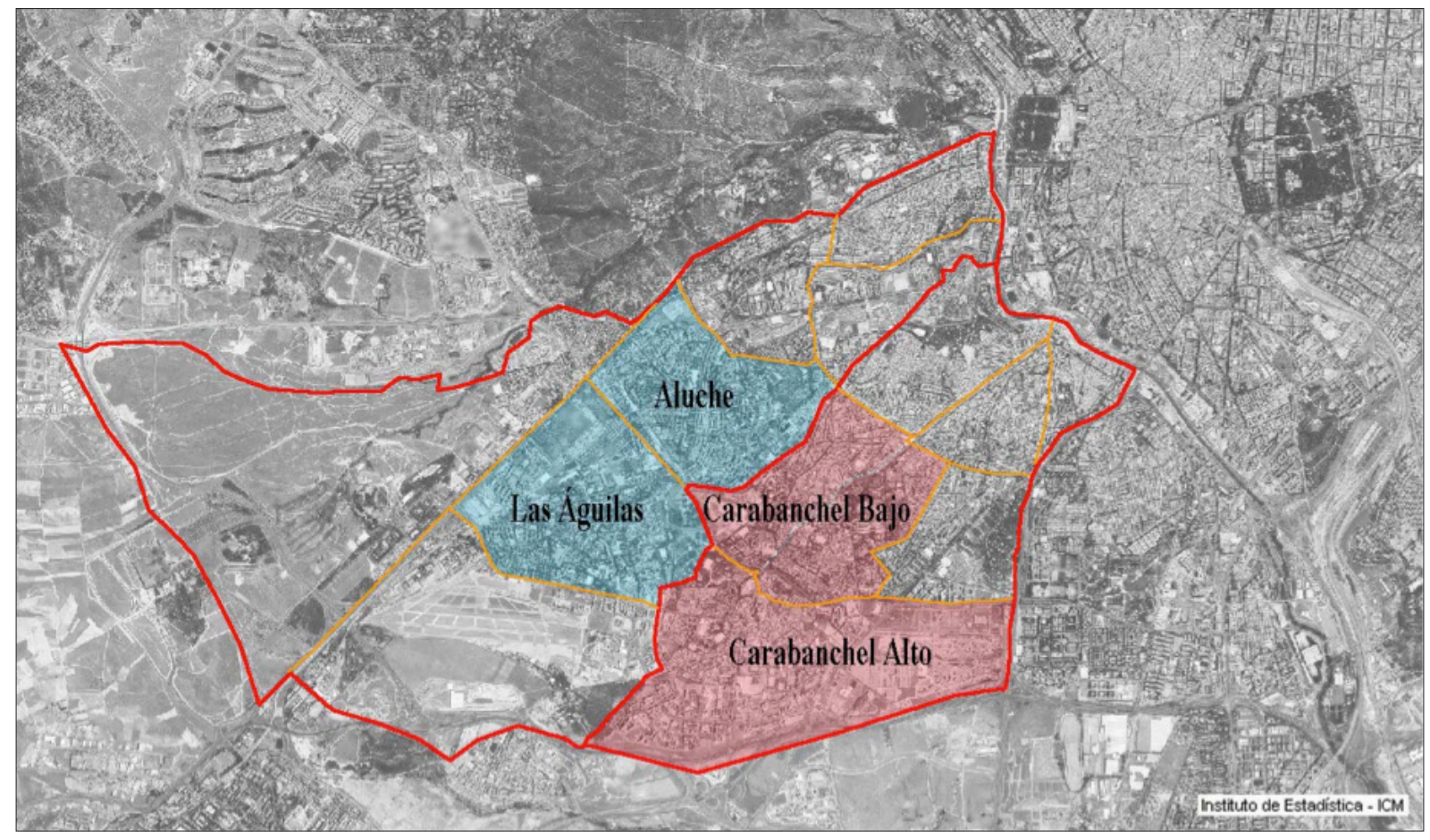

Figura 2: División administrativa de los distritos de Carabanchel y Latina con la señalización de los barrios limítrofes con las denominaciones clásicas de los principales barrios del distrito de Carabanchel.

Fuente: Elaboración propia a partir de imagen del Instituto de Estadística de la Comunidad de Madrid. Nomenclátor Oficial y Callejero (http://www.madrid.org/nomecalles/).

Los desequilibrios sociales, los problemas de equipamientos, las condiciones de vida y las condiciones de habitabilidad de la zona profundizaban en la condición fordista de estos barrios. Esto propició la aparición de la Asociación de Vecinos de Carabanchel Alto en 1974, a la luz de la Ley de Asociaciones de 1964, que se centraría en las reclamaciones por los problemas de suministro eléctrico, agua y falta de equipamientos. Así, este movimiento vecinal se convirtió en expresión de la movilización política contra el régimen dentro una movilización eminentemente obrera que articuló una identidad barrial en base a criterios de clase ${ }^{21}$. A partir de esa década, Carabanchel se convertiría en referente y ejemplo de la barriada fordista periférica convertida en expresión fundamental de la trama urbana asolada por problemas de pavimentación, saneamientos, recogida de residuos, suministros y equipamientos sociale $^{22}$ algo que también marcaría la identidad 'carabanchelera' a futuro.

20 Johnston et al, 2000, p. 321-322; Johnston et al, 2009.

21 Martínez i Muntada 2011, p.65.

22 Sequera 2011. 
La conversión definitiva de la Cárcel de Carabanchel como prisión política se configuró a partir de los últimos grandes casos de represión franquista en los años 70 y con las imágenes de la liberación de presos políticos en 1976 y 1977. A partir de ese momento, la vinculación con la represión franquista se transformó en un imaginario de peligrosidad e inseguridad derivado de la presencia de la propia prisión en una trama urbana totalmente integrada donde la cárcel aparecía rodeada de edificaciones, calles, comercios, parques y jardines; y del aumento de la "porosidad" entre el interior y el exterior donde la figura del drogodependiente actuaba como parte central del discurso moralizantes sobre los vecinos de la época ${ }^{23}$. En 1998 se produjo el cierre definitivo de la prisión debido a la obsolescencia de las instalaciones que no tenían posibilidad para adaptarse a los requisitos establecidos en la Ley Orgánica 1/1919, de 26 de Diciembre, General Penitenciaria y a un planeamiento urbano que buscaba una solución de la situación de la prisión dentro de la trama urbana.

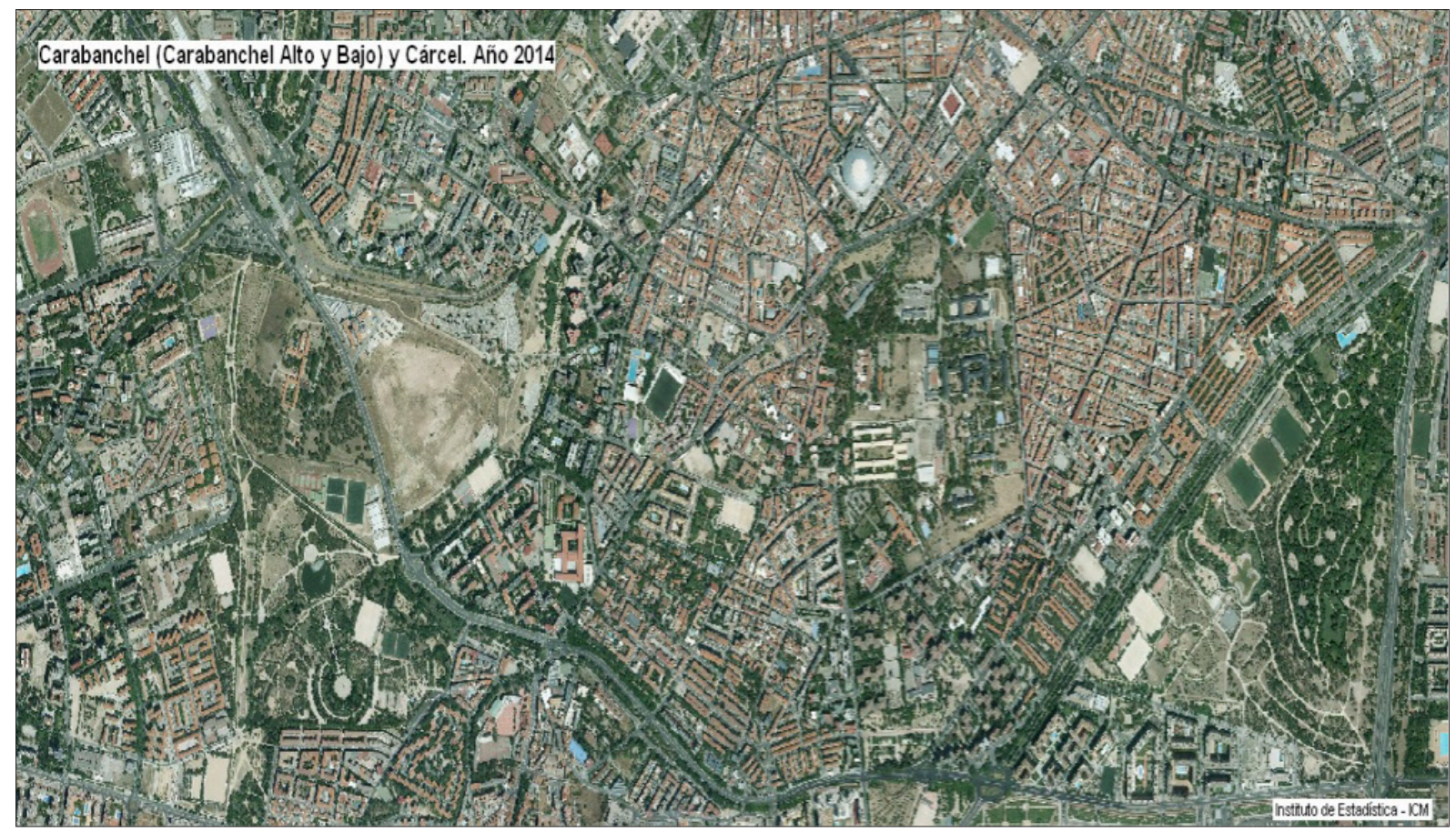

Figura 3: Distrito de Carabanchel en el año 2014 con el solar donde estaba la antigua Cárcel de Carabanchel.

Fuente: Instituto de Estadística de la Comunidad de Madrid. Nomenclátor Oficial y Callejero (http://www.madrid.org/nomecalles/).

La concepción del espacio a través de la planificación urbana e institucional que buscaba establecer una normatividad para el espacio se concretó en el Plan General de Ordenación Urbana de 1997. Los objetivos de este plan pasaban por la construcción de viviendas y la adaptación del viario público en los terrenos de la Cárcel de Carabanchel reduciendo el espacio a un área residencial periférica donde se daba preferencia a la construcción de viviendas en lugar de servicios públicos y equipamientos. El plan establecía un Área de Planeamiento Remitido que supeditaba la

23 García 2013, p.142-143. 
proyección de los terrenos de la cárcel a un acuerdo posterior entre el Ministerio del Interior y el Ayuntamiento de Madrid.

La articulación de una planificación urbana sobre los terrenos de la cárcel provocó una movilización vecinal que demandaba el destino de los mismos para la edificación de equipamientos públicos para dar cobertura a un barrio marcado por la desigualdad social e infraestructural.

El eje central de estas demandas en un primer momento fue la reclamación de un Hospital Público. Tras diez años de abandono de la cárcel y bajo una intermitente presencia de la movilización social, se firmó el Protocolo gubernamental que estableció el destino final de los terrenos, incluyendo alguna reivindicación vecinal, pero manteniendo el carácter residencial y de consumo del espacio. Un espacio al que no se conseguía descargar de la idea de inseguridad y peligrosidad debido a la presencia en el proyecto de las futuras Oficinas de Instituciones Penitenciarias y del Centro de Internamiento de Extranjeros. En octubre de 2008, la Cárcel fue demolida dejando, hasta día de hoy, un enorme solar abandonado.

\section{Espacio, ¿quién lo produce? ¿Quién lo vive?}

La demolición de la prisión en el año 2008 no acabó ni con la reivindicación ni con las movilizaciones sociales de presos y vecinos. De esta manera, este grupo se apropió de los terrenos de la prisión por medio de distintos homenajes, concentraciones e, incluso, por medio de la creación de un lugar de homenaje y memoria denominado 'Jardín de la Memoria'. Esta construcción supondría una práctica que partía de una visión de la prisión cargada de un relato memorial que se quería recuperar. Una visión que venía, como se verá, de un espacio vivido que se oponía a la concepción institucional.

\section{El espacio concebido para Carabanchel}

La concepción institucional del espacio que se proyectó para los terrenos que ocupaban la antigua Cárcel de Carabanchel se concretó a través de una serie de elementos de planificación. El PGOUM de 1997 y, más concretamente, el A.P.R. 11.01 'Cárcel de Carabanchel' -como expresión última del proyecto urbano en los terrenos de la antigua prisión- actuaban como una verdadera concepción del espacio a través de la cual la planificación permitía la producción y reproducción del proceso de acumulación capitalista alejándose de ser elementos objetivos, neutrales y técnicos ${ }^{24}$.

Por lo tanto, este proyecto de planificación urbana, tanto el inicial como el protocolo posterior, configuraba una concepción en base a supuestos criterios técnicos y objetivos que portaban la intencionalidad normativa de crear un área residencial y dotacional que eliminaba la prisión, tanto para la obtención de una amortización por la venta de los terrenos como para eliminar un patrimonio, que desde el punto de vista de los relatos del pasado, resultaba 'incómodo'25.

24 Johnston et al, 2000, p.435-436.

25 Meskell 2002; Sánchez 2013, p.30. 


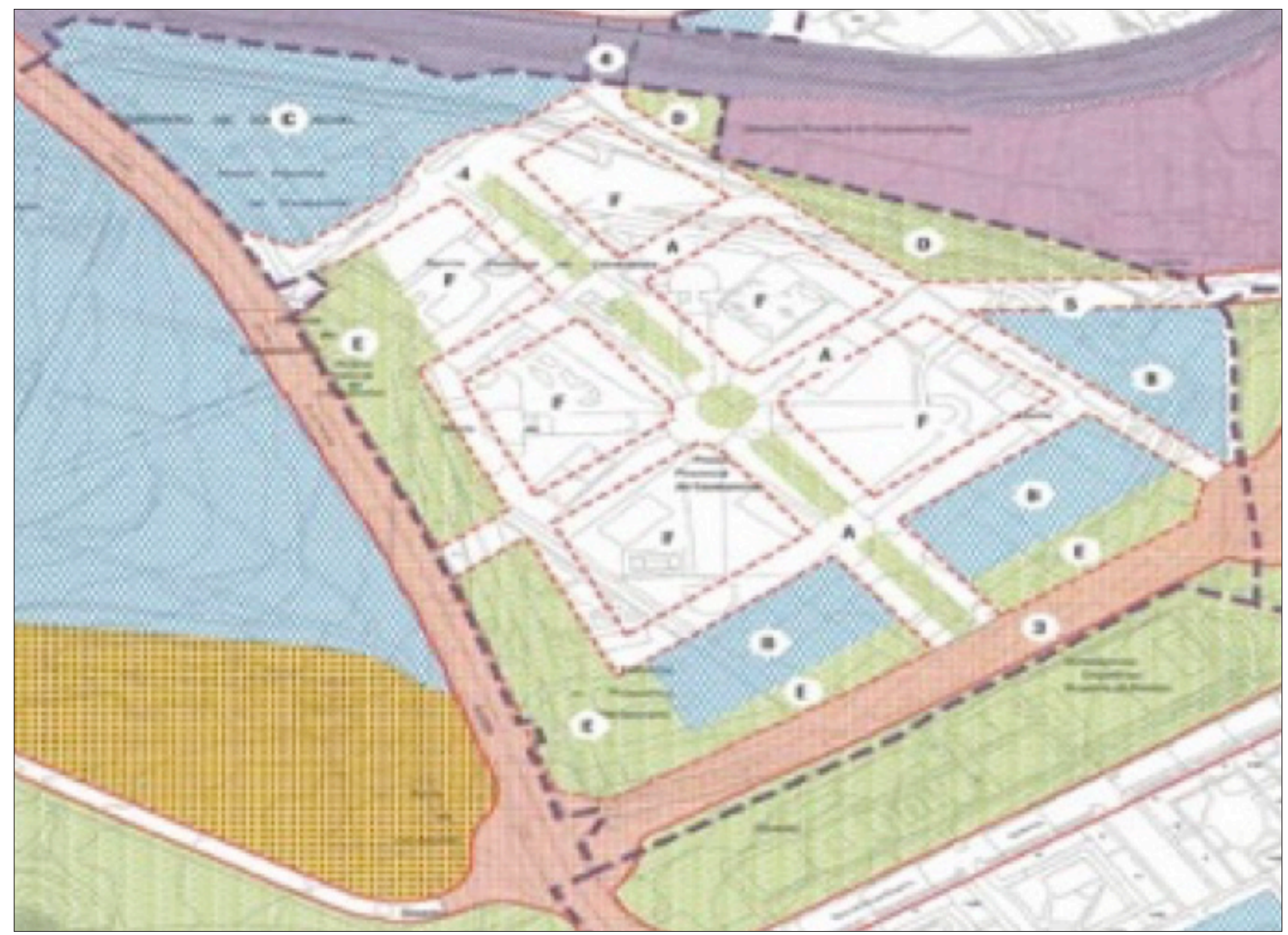

Figura 4: Proyecto para la Cárcel de Carabanchel incluido en el Plan General de Ordenación Urbana de Madrid de 1997.

Fuente: PGOUM 1997.

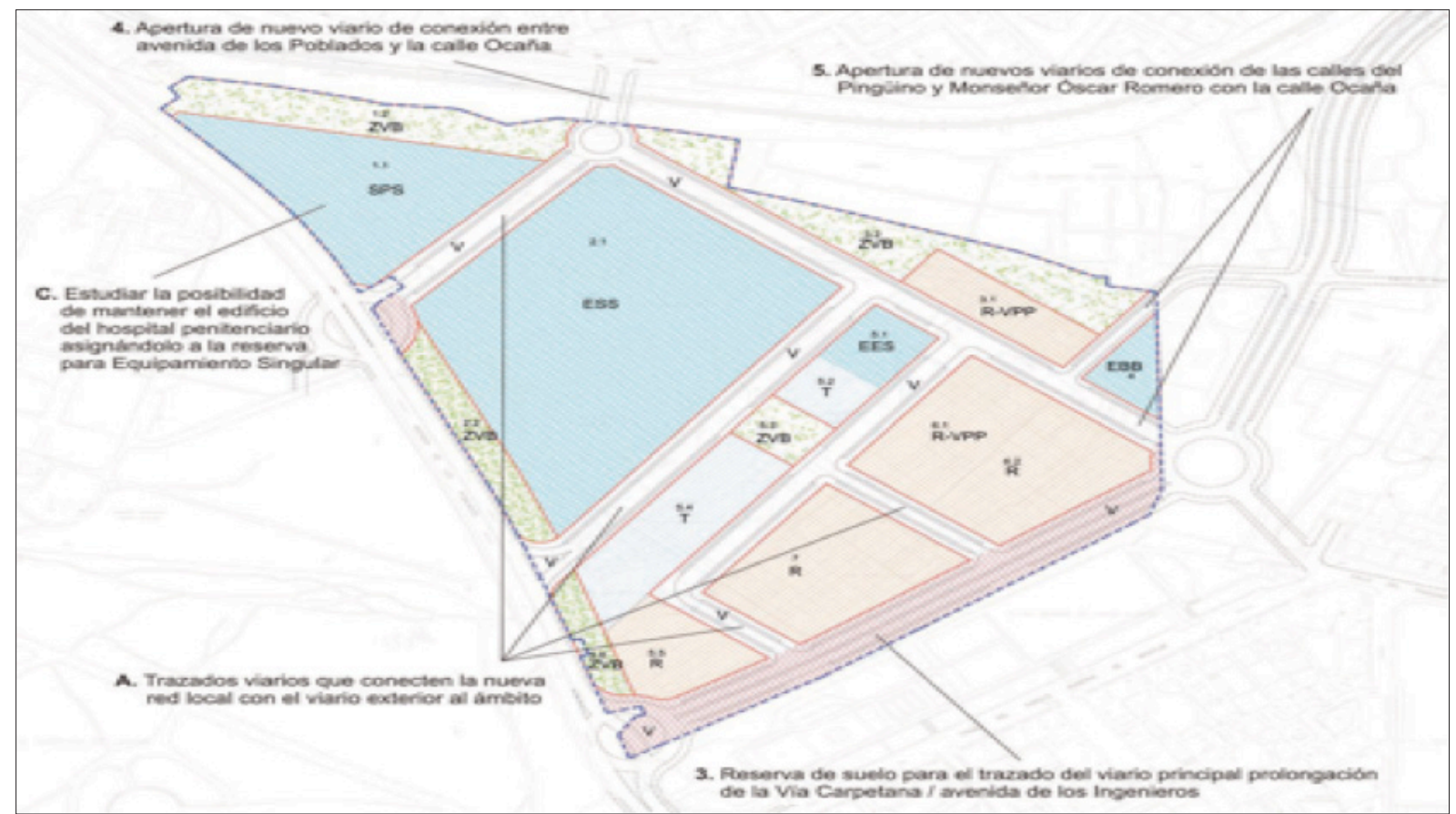

Figura 5: Protocolo de actuación para el Área de Planeamiento Remitido 11.01 "Cárcel Carabanchel". Fuente: Ayuntamiento de Madrid. 
Así, esta planificación establecía unos usos normativos para el solar que se convertiría en parte de la trama urbana, por un lado un espacio residencial, marcado por la presencia de una gran cantidad de espacio para viviendas, un espacio de tránsito, por medio de la configuración de un viario público que permitía la unión con la trama ya creada, y de consumo, por la futura existencia de servicios y comercios. Desde el análisis se ha podido observar cómo la impronta técnica y objetiva de la planificación urbana estaba atravesada por una intencionalidad política que suponía que este proyecto normativo buscara la eliminación del estigma carcelario protagonizado por la cárcel, la obtención de plusvalías, la homogeneización del espacio y la imposición de un relato sobre el pasado. En definitiva, el plan urbanístico buscaba conseguir el control simbólico del espacio y poder determinar qué elementos podían aparecer en el mismo así como su uso final, eliminando cualquier singularidad del lugar vinculada al espacio vivido, el cual aparecería en la disputa a través de las reclamaciones vecinales por establecer el futuro de los terrenos. Se creaba un discurso ideológico sobre el espacio a través de una planificación amparada en criterios técnicos que marcaban que Carabanchel quedaría como un espacio periférico residencial al que no se le privaba de su estigma carcelario, puesto que se mantenían elementos relacionados con el sistema penitenciario, y que seguía marcado por el desequilibrio social y infraestructural donde no habría nada considerado positivo únicamente "desequipamientos" y "mierda" 26 dentro de un barrio fordista.

La eliminación del estigma carcelario, no conseguido, buscaba el control simbólico del espacio al que se le dotaba de un nuevo significado que debía determinar la percepción y vivencia del espacio. Uno de los elementos fundamentales para este control simbólico partía de la eliminación de la prisión como forma de abandonar un determinado discurso del pasado, que la vinculaba con la represión y con la resistencia antifranquista, implementando un urbanismo amnésico ${ }^{27}$ que buscaba la pacificación del espacio por medio de un proceso de rectificación ${ }^{28}$. Si la materialidad de la cárcel dejaba de existir y en su lugar se establecía una trama urbana que continuaba la existente, el relato del pasado dejaba de estar presente en ese lugar que perdía toda conexión con una determinada memoria política. Por lo tanto, con el análisis del caso de Carabanchel, se observa que este proceso de planificación, a través del cual se configura una concepción del espacio, está relacionado con la reconfiguración de los relatos del pasado que se convierten en hegemónicos y oficiales. Lo que puede aparecer en el espacio público y lo que éste 'cuenta' a través de ciertos elementos materiales responde a decisiones concretas intencionales. Este tipo de proyectos de planificación permiten que unas narrativas específicas se conviertan en dominantes al mismo tiempo que la concepción del espacio busca imponer una normatividad al uso y percepción del mismo estableciendo un relato que

26 Expresiones utilizadas por los informantes durante las entrevistas realizadas en el trabajo de campo de la investigación para referirse al desequilibrio infraestructural y la desigualdad en equipamientos.

27 Suárez y Galante 2008, p.95.

28 Foote 1997. 
se pretende aparezca como objetivo, neutral y verdadero. En el caso de la Cárcel de Carabanchel se pone de manifiesto que la producción del espacio tenía como uno de los objetivos la imposición de una determinada memoria política puesto que la eliminación de un símbolo de la represión franquista marcaba que ese relato del pasado dejaba de tener un elemento material de referencia. Por lo tanto, esta imposición de una memoria fuerte, siguiendo la concepción de Traverso ${ }^{29}$, se buscaba a través de la rectificación del lugar mediante un proyecto urbanístico que eliminaba los restos materiales de la cárcel imponiendo un uso y significado normativo de los terrenos. Carabanchel quedaba vinculado a una representación institucional específica que no necesariamente estaba relacionada con la percepción y vivencia diaria de sus habitantes -o de los ex presos.

Este proyecto urbano, para eliminar el estigma negativo y la materialidad incómoda que suponía la cárcel, buscaba crear una renovación urbana desde la teórica ausencia de connotaciones ideológicas y políticas. Algo que marcaba una división entre lo que se consideraba auténtico y real, aquello proyectado técnicamente, y lo que se consideraba político e ideológico que era lo ficticio, en este caso, el mantenimiento de un relato del pasado. Así, el Plan Técnico que debía ocupar el Área de Planeamiento Remitido no cubría ninguna de las necesidades o demandas de los vecinos estableciendo una normatividad que incluso codificaba técnicamente los espacios proyectados a través de una objetividad planificada. De esta manera, estos códigos neutros alejaban la realidad proyectada de la vivencia del espacio que tenían -y tendrían- los vecinos. El PGOUM hablaba de un 'equipamiento singular' que se codificaba como SPS (Servicio Público Singular) cuando la realidad marcaba la proyección del Centro de Internamiento de Extranjeros y la Comisaria. También se hacía mención al ESS (Espacio de Salud Singular), al EES (Espacio de Educación Singular) y el EBB (Espacio de Bienestar Básico). La parte del proyecto destinada a viviendas se codificaba a través de la denominación técnica ' $R$ '. Así, el solar quedaba codificado de una forma técnicamente legible de forma objetiva al margen de la vivencia del espacio eliminando la presencia de la cárcel y camuflando la finalidad real de cada parte del proyecto. Siguiendo las ideas lefebvrianas sobre la concepción del espacio, el lenguaje pretendidamente aséptico y neutral invisibilizaba las decisiones políticas sobre el destino de los terrenos. Por medio de una representación, que buscaba la normatividad y distribuía el suelo por sus usos proyectados en base a códigos, se eliminaba la tensión y la disputa por los usos del solar así como la potencialidad de alternativas e intereses en conflicto por el uso del espacio ${ }^{30}$. El Protocolo de actuación en el A.P.R 11.01 creaba un espacio homogéneo que completaba la trama urbana eliminando el lugar emblemático de la cárcel.

La idea de la concepción del espacio orientada a los procesos de acumulación capitalista por medio de su producción también podemos encontrarla en el caso de la demolición de la Cárcel de Carabanchel puesto que el proyecto buscaba la obten-

29 Traverso 2007.

30 Martínez 2013, p.24. 
ción de una renta por la venta del solar. Las plusvalías por la venta del suelo estaban contempladas en el proyecto institucional a través de una política de amortización de centros penitenciarios obsoletos que permitiría la obtención de beneficios financieros. Esta especulación con los terrenos muestra cómo se considera la cárcel por su valor de cambio y no por sus potencialidades de uso, entendiendo, como señalaba Lefebvre ${ }^{31}$, el espacio como una mercancía dentro del proceso de acumulación que beneficia, en este caso, al sector inmobiliario. Esta búsqueda del aprovechamiento económico junto con la necesidad de proyectar un espacio planificado como lugar de tránsito y conexión permitían que se configurara lo que Hiernaux denomina espacio objetivable del capitalismo ${ }^{32}$ que respondía a la lógica económica y establecía una forma hegemónica de vivir ese espacio condicionando las prácticas sociales ${ }^{33}$. Por lo tanto, de nuevo, el proyecto de reforma del solar de la cárcel de Carabanchel, según estaba contemplado en el PGOUM y en el protocolo de actuación en el A.P.R.11.01, configuraba un espacio que pretendía aparecer como dado a priori en base a criterios técnicos imponiendo un uso y unos significados por encima de la vivencia del mismo.

El proyecto también permitía afianzar la proyección simbólica hacia el exterior que iba a tener el barrio -y el distrito- de Carabanchel. La representación de Carabanchel ha pasado por una serie de ejes que se han centrado en la persistencia de la idea de inseguridad proyectada mediáticamente -junto con el proyecto de las Oficinas de Instituciones Penitenciarias y el CIE-, en su carácter residencial donde los proyectos de revalorización pasan por la vivienda -por ejemplo, la aparición del PAU- y el consumo -con el Centro Comercial Isla Azul. La representación institucional también han potenciado una serie de lugares patrimoniales a través de videos de promoción, guías turísticas y espacios señalados como son Madrid Río, la Ermita de San Isidro y la Ermita de Nuestra Señora de la Antigua, dejando otros lugares, que son señalados por los vecinos, al margen de dicha proyección.

En el caso de la Cárcel de Carabanchel, esta marginación de la misma como elemento presente entre el catálogo de lugares emblemáticos pasó también por una pacificación de la prisión por dos vías; primeramente, por su eliminación, y, segundo, por la proyección de una placa memorial en una de las plazas del futuro proyecto urbanístico como único recuerdo estático a la presencia anteriormente en ese espacio de la cárcel. Los estudios han señalado que se debe entender que existen lugares marcados por el trauma y la represión ${ }^{34}$, algo que los convierte en espacios incómodos que suscitan diversos tipos de actuaciones, en este caso, una eliminación para acabar con ese relato relacionado con el trauma y la violencia. Estas decisiones sobre el espacio, convierten las políticas urbanas en políticas de memoria ${ }^{35}$, por lo tanto, éste aparece como un vehículo de la memoria, es decir, se recupera la

31 Lefebvre 2013 [1974], p.350.

32 Hiernaux 2004.

33 Martínez 2013. p.43.

34 Compañy y Biasatti 2011; Till 2008.

35 Withers 2004, p.317. 
memoria a través de aquellas materialidades que adquieren sentido y significado por las acciones y discursos de los grupos ${ }^{36}$. La eliminación de la cárcel pacificaba el espacio borrando los aspectos traumáticos y determinaba un espacio público que expulsaba del mismo una memoria conflictiva para mantener el capital simbólico desde el cual se iba a dar legitimidad a la memoria política que, desde la transición, había marcado el sistema política actual. Esta memoria fuerte estaba marcada por el abandono de la recuperación del pasado y el mantenimiento de los principios de consenso y reconciliación, también a nivel simbólico, de finales de los años 70. Así, se potenciaba una 'buena memoria' que no imponía el silencio sino dejaba en suspenso cualquier recuerdo al pasado traumático ${ }^{37}$.

La colocación proyectada de una placa memorial en una de las vías planificadas suponía otra forma de pacificación puesto que acababa con la disputa por la memoria y eliminaba cualquier tipo de práctica que permitiera una labor de recuperación y reactualización del pasado de manera constante en el tiempo. La placa memorial fijaba para el futuro una única forma de mirar al pasado vinculado con la prisión y creado desde un discurso de consenso.

\section{La aparición de un contraespacio vecinal}

La ausencia de la materialidad, a partir de octubre de 2008 cuando la Cárcel fue derribada, no supuso un fin del conflicto puesto que quedó un remanente ${ }^{38}$, en este caso, la cárcel -y el solar vacío después- actuando como un contraespacio dentro del espacio vivido por los vecinos. Este conflicto constante permite que estos remanentes se conviertan en lugares emblemáticos cargados de simbolismo y significados desde ese espacio vivido. Lugares que se convierten en centros afectivos dentro de los espacios de representación ${ }^{39}$. De esta manera, la cárcel de Carabanchel se convirtió en un lugar emblemático -y convocante- dentro de un espacio vivido articulado en torno a tres ejes: la memoria de independencia municipal previa, la identidad obrera dentro de un barrio fordista caracterizado por la falta de equipamientos y, por último, el estigma de la inseguridad y la peligrosidad que marcaba desde el exterior la configuración identitaria de los vecinos una vez que esta vinculación fue "asumida e interiorizada"40. Desde este espacio de representación se habían configurado una serie de códigos, símbolos, conmemoraciones, ritos y lugares que se interrelacionaban con la identidad y la memoria de los vecinos de Carabanchel. Así, la cárcel, se configuraba como un lugar fundamental para entender el barrio y, a su vez, se incluía dentro de un catálogo de lugares que eran apropiados por los habitantes del mismo.

Desde el anuncio del cierre a finales de los año 90, los movimientos vecinales iniciaron un proceso de reclamación de los terrenos de la cárcel de Carabanchel.

36 Jelin y Langland 2003, p.11.

37 Vinyes, 2009, p.35.

38 Till 2010, p.77.

39 Lefebvre 2013 [1974], p.100.

40 Ortíz 2013, p.54. 


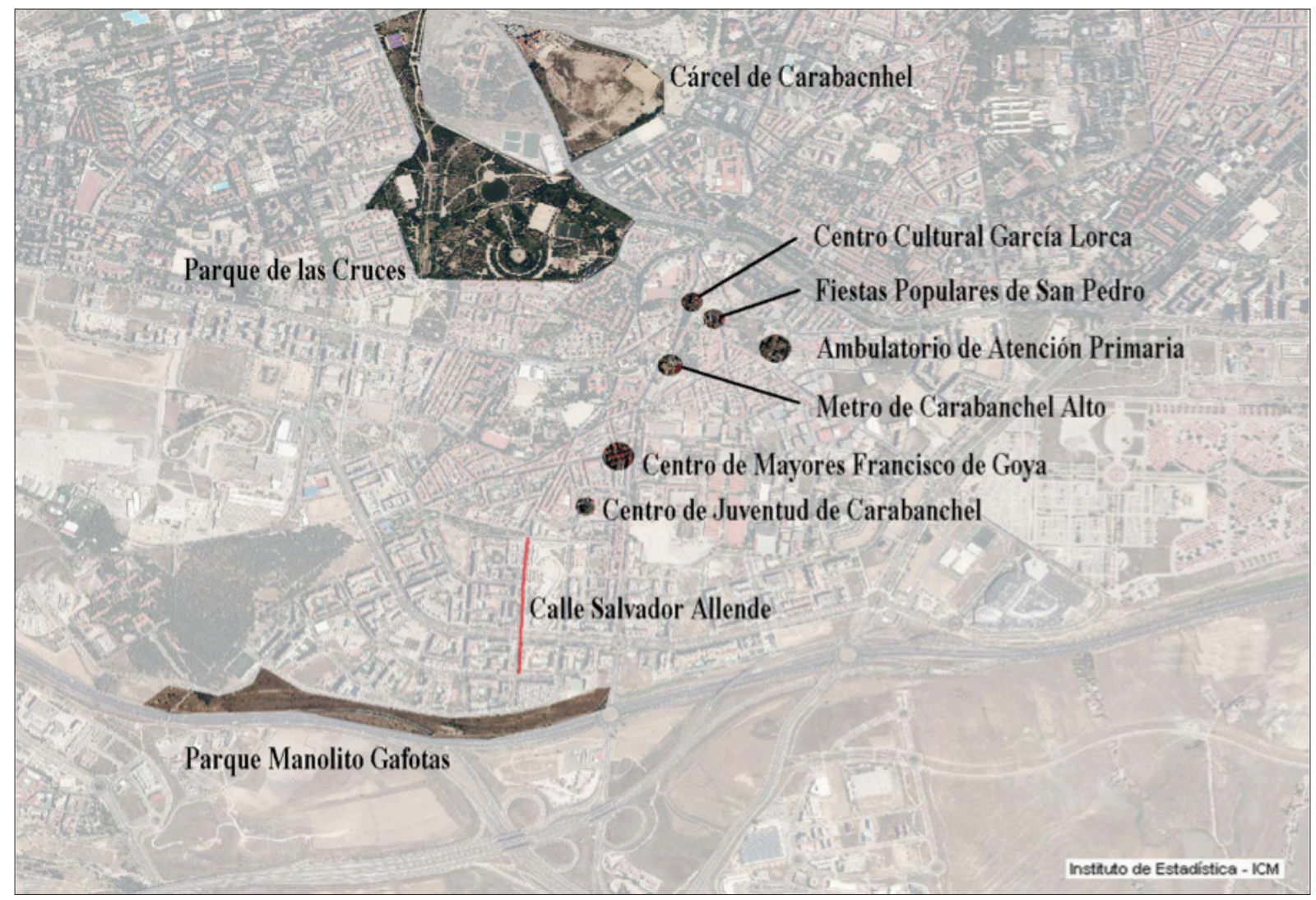

Figura 6: Mapa de Carabanchel Alto donde aparecen señalados los lugares 'carabancheleros', es decir, aquellos lugares emblemáticos por estar asociados a las reivindicaciones y significados de los vecinos.

Fuente: Elaboración propia a partir del visor del Instituto de Estadística de la Comunidad de Madrid.

En ese primer momento, las reivindicaciones se centraron en la demanda de nuevos usos para esos terrenos. Usos que debían estar relacionados con paliar la falta de equipamientos públicos y de servicios sociales que caracterizaban Carabanchel. Estas primeras manifestaciones portaban unas demandas por los usos del solar que eran generalistas pero se escenificaron en la reclamación de un Hospital público en los terrenos. El hospital aparecía como una ejemplificación de las demandas de unos vecinos que habían interiorizado la necesidad de reclamar aquellos equipamientos que consideraban escasos en la zona. Carabanchel se había configurado desde los años 60 como una periferia urbana ejemplo del urbanismo fordista, un imaginario de barrio popular que, con el crecimiento demográfico y urbano de los años 60 y 70 , derivó en una identidad de clase trabajadora ${ }^{41}$. Identidad que no sólo procedía de las características sociodemográficas del crecimiento de la época sino de un espacio vivido caracterizado por las desigualdades urbanas, la falta de equipamientos y la escasez de servicios sociales. Así, se generaba una situación permanente en el tiempo de trato desigual y de agravios comparativos que llevaban a una constante movilización vecinal desde estas ideas.

41 García 2008. 
De esta manera, la concreción de estos elementos identitarios se plasmaron en la reclamación del uso de los terrenos de la cárcel, es decir, de un espacio de representación articulado en torno a esta identidad fordista surgían una serie de demandas que convirtieron a la cárcel en un lugar reclamado dentro de la lista de lugares emblemáticos del barrio por estar asociados a la lucha vecinal. La cárcel se convirtió en un 'rallying point'42, un lugar fundamental dentro de los espacios más simbólicos del barrio. Un lugar que se podía denominar como 'carabanchelero'.

Esta dinámica de reclamación en base a criterios derivados de las necesidades y de lucha contra la desigualdad infraestructural permite comprender las demandas de los vecinos como partes integrantes de un espacio vivido que define éste en base a su valor de uso, en oposición a una concepción gubernamental que potencia los aspectos económicos, de beneficios financieros y de explotación comercial dentro de una visión del espacio por su valor de cambio ${ }^{43}$. Así, aparecía una oposición a un tipo de urbanismo periférico que daba una gran importancia al aspecto especulativo, siendo un sector fundamental en esta forma de concebir el espacio la orientación del mismo hacia lo residencial. Como se ha mencionado más arriba, la concepción gubernamental se orientaba a circunscribir a Carabanchel como un espacio residencial y de consumo donde las demandas vecinales no podían definir el proyecto urbano debido a una correlación de fuerzas que impedía su participación en la toma de decisiones públicas.

“...tu ve por aquí o por Aluche y ves casas, casas, casas, un parque, casas, casas, casas, es decir, de alguna forma, ¿tú tienes algún atractivo para vivir en este barrio? ¿Tienes alguna cosa que te lleve a decir 'este barrio tiene'?". ${ }^{4}$

Este conflicto entre la concepción y la vivencia, entre dos formas de entender el espacio, se materializaba en estos lugares emblemáticos que estaban cargados de significado y simbolismo para los vecinos, puesto que estaban enraizados en su vida cotidiana, y que eran entendidos por las autoridades en base a otras lógicas de producción y uso. La disputa por estas materialidades afectaba a las identidades y las memorias colectivas de los vecinos en su vida cotidiana en lo que Fullilove denomina 'root shock of forced removal'45. Por lo tanto, es desde la vida cotidiana desde donde nace la resistencia, es decir, desde el espacio vivido se articulan las resistencias.

\section{El estallido de la memoria colectiva de la Cárcel}

A partir del año 2006, las reivindicaciones en torno a la cárcel aumentaron, ante su inminente derribo, y modificaron sus características principales. La aparición del movimiento por la recuperación de la memoria histórica influyó enormemente en

42 Foote 1997.

43 Lefebvre 2013 [1974], p.350.

44 Extracto de entrevista realizada a uno de los informantes durante los trabajo de campo de esta investigación.

45 Fullilove 2004. 
la forma de entender la Cárcel de Carabanchel. Si ésta se había convertido en un lugar convocante dentro del movimiento vecinal del barrio debido a la reivindicación por su apropiación por los vecinos; a partir de ese momento se unió a esta idea la reclamación de la memoria de la cárcel dentro de un palimpsesto de discursos. Por ello, a estas movilizaciones se unieron en ese año los antiguos presos del franquismo creando un movimiento heterogéneo unido en torno al lugar convocante de la cárcel. Además, en ese momento los vecinos empezaron a entrar dentro de la prisión a realizar manifestaciones, visitas guiadas, concentraciones, todas ellas formas de apropiación del espacio. Este tipo de prácticas también acabaron con el carácter heterotópico ${ }^{46}$ de la prisión y permitieron que no fuera un lugar ajeno a los vecinos sino un lugar conocido y que era escenario de sus reclamaciones. Así, a través de su ocupación de la cárcel, ésta ya no era sólo un lugar emblemático sino un lugar emblemático positivo dado que ya no era el espacio del estigma sino el espacio convocante donde se reunían y donde se reconocían como un grupo -algo especialmente importante para la conformación de la identidad de los ex presos.

La cárcel pasaría de ser un lugar reclamado por su uso y la necesidad de equipamientos a ser un lugar emblemático propio de los vecinos, positivizado, escenario de sus reivindicaciones y, además, un elemento patrimonial para el barrio cuya conservación permitiría no sólo recuperar su memoria sino también convertirla en un símbolo barrial. Esta positivación se concretaba en un proyecto vecinal que se oponía a la planificación institucional establecida en el PGOUM y en el Área de Planeamiento Remitido. Este proyecto incluía un museo de la memoria, un parque, un Hospital, una facultad universitaria y otros equipamientos públicos. La cárcel se entendía, a partir de este momento, como un elemento patrimonial por dos razones, por un lado, por sus valores histórico-artísticos dentro de sus elementos arquitectónicos singulares -la cúpula y su forma radial fundamentalmente-, y, por otro lado, por su vinculación con la recuperación de la memoria de la represión franquista. La realización del trabajo de campo permitió situar el discurso patrimonial dentro del movimiento social que reclamaba la conservación de parte de la prisión dentro de un proyecto urbano de recuperación del solar junto a otros equipamientos sociales. Se señalaba la prisión como patrimonio de Carabanchel dentro de un conjunto de sitios emblemáticos en el barrio relacionados con su conservación patrimonial, como son la Colonia de la Prensa, la Ermita de Nuestra Señora de la Antigua, la plaza del antiguo Ayuntamiento de Carabanchel Bajo y los restos de las fincas de recreo de la nobleza durante los siglos XIX y XX.

Esta señalización patrimonial que demandaba la demarcación de una serie de elementos positivos para el barrio buscaba oponerse al estigma carcelario que se había configurado desde el exterior y que se mantenía con el proyecto gubernamental a través de la presencia del Centro de Internamiento de Extranjeros. De esta manera, a partir del derribo de la cárcel, la reclamación por el cierre del CIE se convirtió en un elemento más dentro del conjunto de demandas de los vecinos. A partir del año

46 Foucault 1986; Cairo 2004; Rodríguez 2006, p.172; Ortiz 2013. 
2014 esta demanda se intensificó puesto que la reclamación giró en torno a la perpetuación del estigma carcelario que el CIE arrojaba sobre los terrenos.

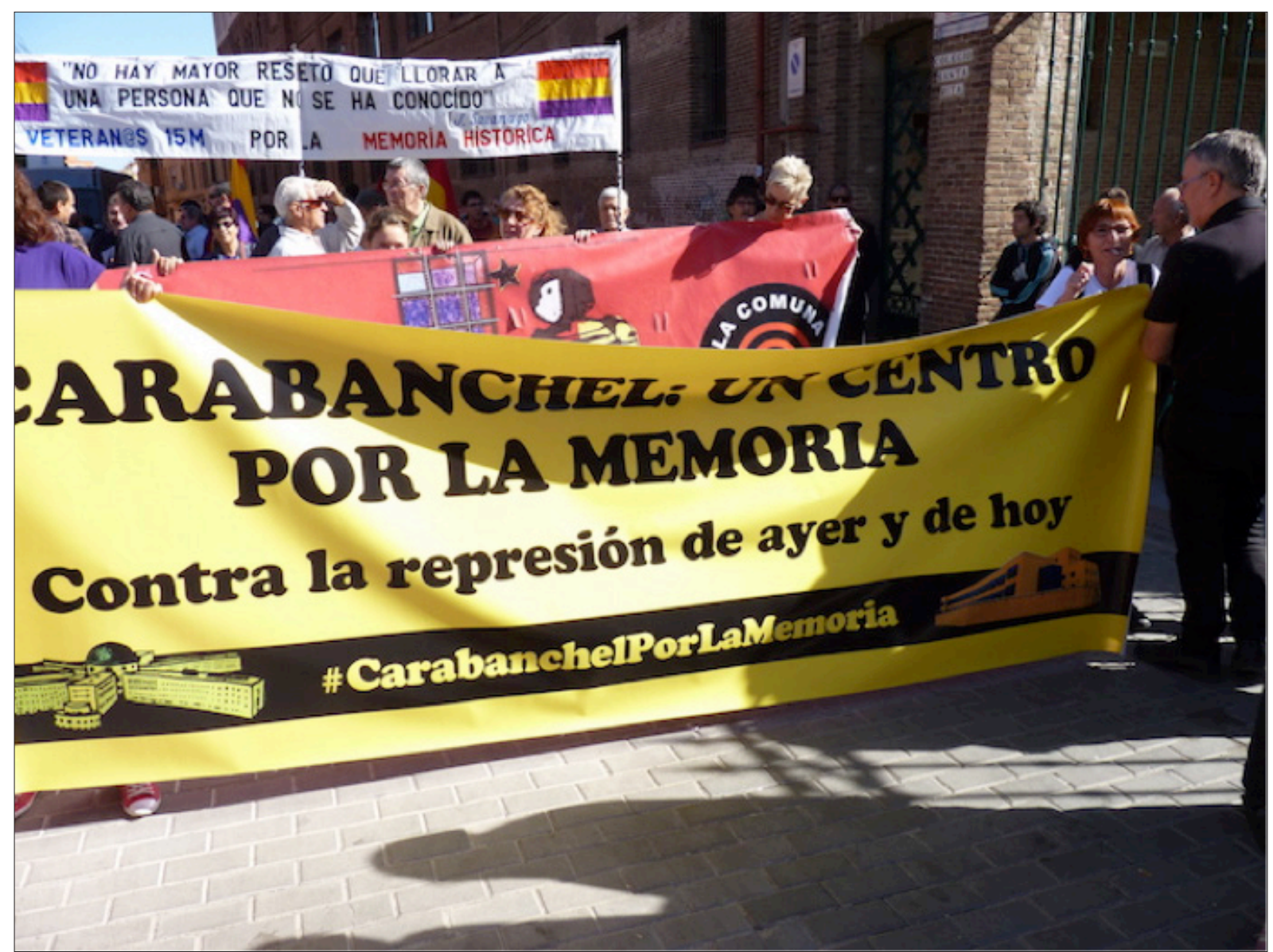

Figura 7: Manifestación en Octubre de 2014 en el aniversario del derribo de la Cárcel de Carabanchel donde la demanda por el cierre del CIE está presente a través del lema de la lucha contra la represión.

Fuente: Autor.

\section{La performatividad del espacio vivido vecinal}

Esta señalización de la prisión -de los terrenos de la misma una vez que se produjo el derribo- como un elemento incorporado a los lugares 'carabancheleros' y como un lugar que formaba parte del patrimonio de Carabanchel se materializó en dos prácticas espaciales que hacían tangible la percepción que existía de ese espacio vivido. La primera de las prácticas fue la construcción de una réplica de la prisión y la colocación de una placa en uno de los laterales del solar en forma de memorial que se denominó 'Jardín de la memoria'. La segunda se concretó en la incorporación de la cárcel a un proceso de señalización patrimonial popular que marcaba con placas aquellos lugares que eran simbólicos para los vecinos, creando un itinerario patrimonial que atravesaba Carabanchel. Se señalaban de esta manera un conjunto de lugares que estaban relacionados con la memoria de la existencia municipal previa y con los lugares relacionadas con la lucha vecinal. 
Estas prácticas materializaban un espacio vivido configurado en torno a una identidad barrial donde estos lugares tenían un significado concreto. Estos elementos entrecruzados, es decir, la memoria colectiva de existencia municipal previa, las prácticas, la experiencia diaria de un barrio marcado por las desigualdades dotacionales y la situación periférica respecto a Madrid, la identidad obrera/popular y la negociación constante con los discursos y representaciones del barrio, configuraban una identidad espacializada. Por lo tanto, las actuaciones que desde las instituciones se realizaban sobre alguno de estos lugares se interiorizaban como un conflicto por definir qué era el barrio y quién lo producía.

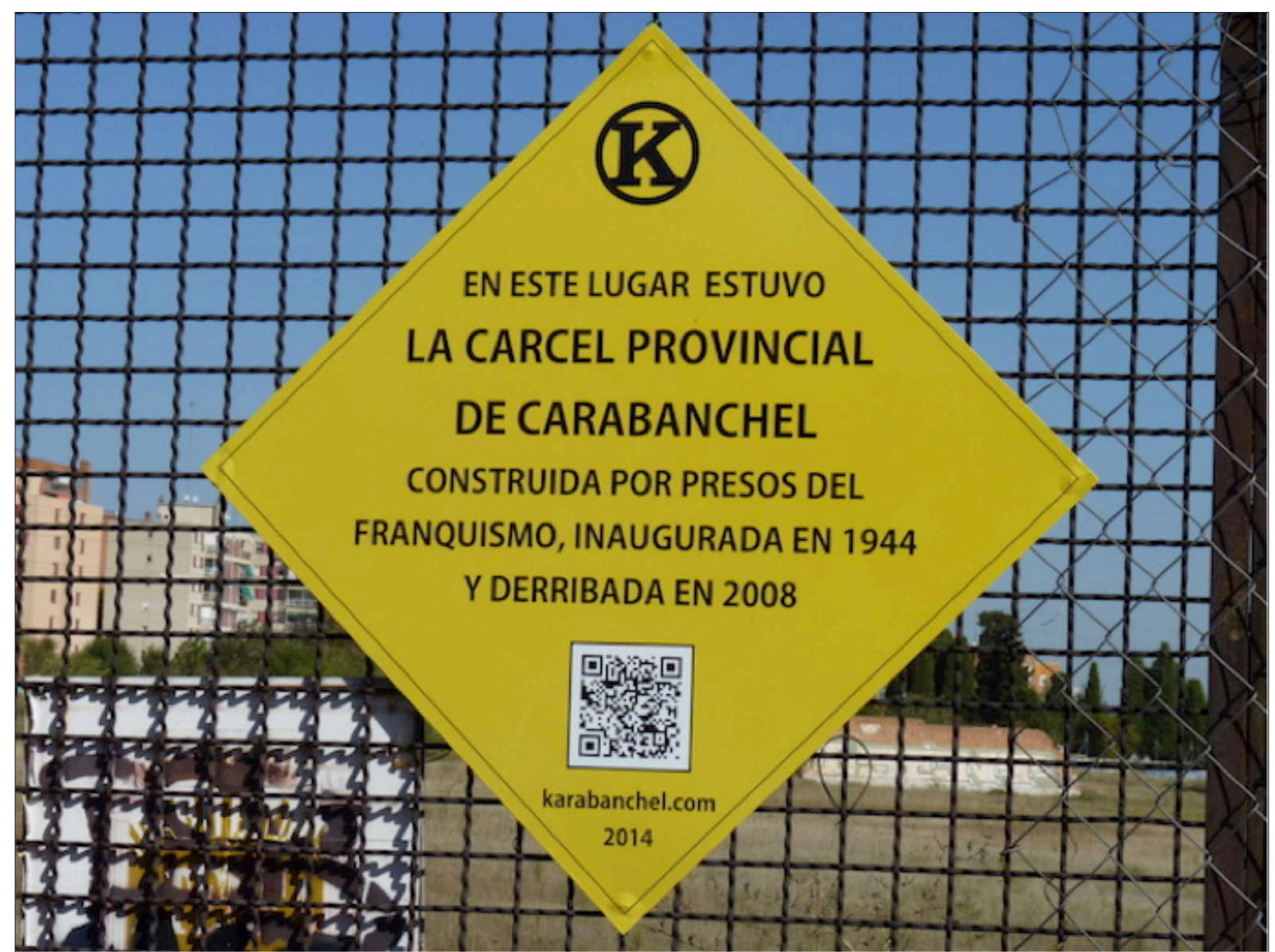

Figura 8: Placa patrimonial popular de los vecinos de Carabanchel.

Fuente: Autor.

Dentro del proceso de movilización, la llegada de los ex presos y la irrupción de las demandas de recuperación de la memoria histórica dentro de la agenda pública supusieron un cambio sustancial del movimiento y de sus reivindicaciones. La identidad vecinal, configurada a partir de una determinada memoria colectiva de las luchas por el barrio, se unió a una memoria colectiva que había quedado marginada del relato oficial configurado desde la transición. La irrupción de los vecinos en el interior de la cárcel supuso la aparición de las demandas de conservación en el mismo momento en el que los antiguos presos franquistas se unieron a las movilizaciones 
y reclamaron la recuperación de la memoria de la cárcel. Así, se articuló un discurso de puesta en valor de la prisión para su futuro uso y su recuperación patrimonial dado que ya no era un lugar restringido, negativo y punitivo sino un lugar de memoria que recuperaba el relato antifranquista, que podía ser usado por los vecinos para acabar con la desigualdad de equipamientos y que se había convertido en uno de los centros afectivos dentro del espacio de representación vecinal ${ }^{47}$. La recuperación de la memoria de la cárcel se oponía al proyecto de su demolición que suponía la eliminación de un relato del pasado vinculado a la represión y la resistencia antifranquista imponiendo una memoria pacificada donde no existía ese conflicto. Por lo tanto, la recuperación de la memoria de la cárcel implicaba la ejecución de una memoria ejemplar ${ }^{48}$ que buscaba una reparación simbólica para las víctimas. En ese momento de la movilización, la cárcel aparecía como un lugar ejemplar y de testimonio que recuperaba hechos traumáticos para facilitar el recuerdo, la reparación, la conmemoración y el aprendizaje ${ }^{49}$.

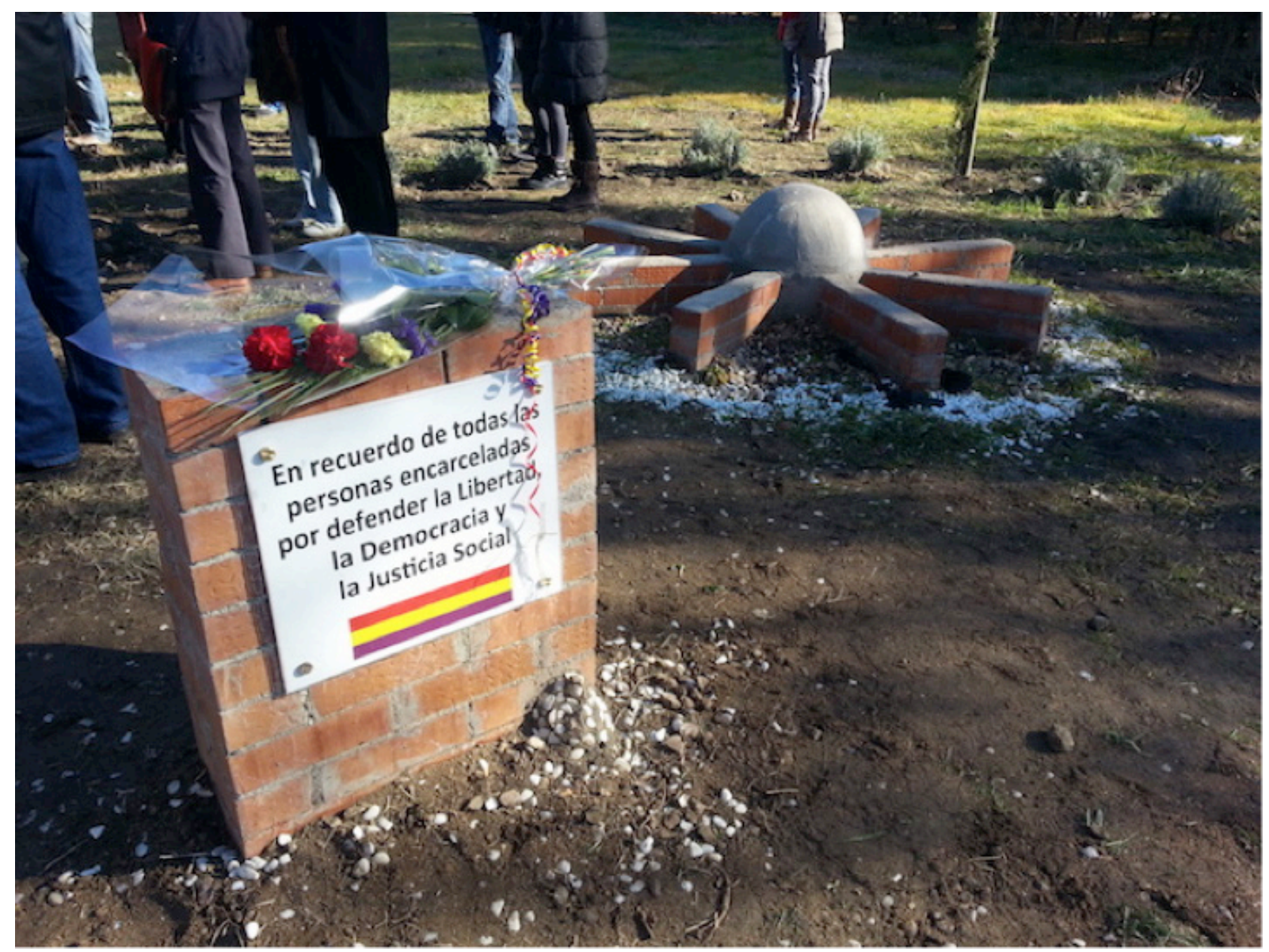

Figura 9: Jardín de la Memoria (réplica de la cárcel y placa memorial). Fuente: Autor.

47 Lefebvre 2013 [1974], p.100.

48 Todorov 1995.

49 Azaryahu 2003; Foote y Azaryahu 2007, p.130-131; Karacas 2010; Hite 2013, p.16. 
La unión de estos dos grupos, la confluencia de las dos memorias, permitió la configuración de un 'nosotros' colectivo que se integraba dentro de un espacio vivido donde la cárcel era un lugar convocante y que daba sentido al movimiento. La integración entre la prisión, los presos y los vecinos se dio en base a la existencia de unos valores compartidos, una memorias vinculadas -porque los presos formaban parte de la memoria vecinal y los vecinos de la memoria subalterna de los presos-, de unas identidades confluyentes -puesto que ambos colectivos reconocían al otro como "parte de los nuestros" o como "antiguos vecinos circunstanciales"50-, y de un lugar que todos reconocían como propio y que, en el caso de los presos, permitía la reconstrucción del grupo, su reconocimiento mutuo y la toma de conciencia de una identidad compartida ${ }^{51}$.

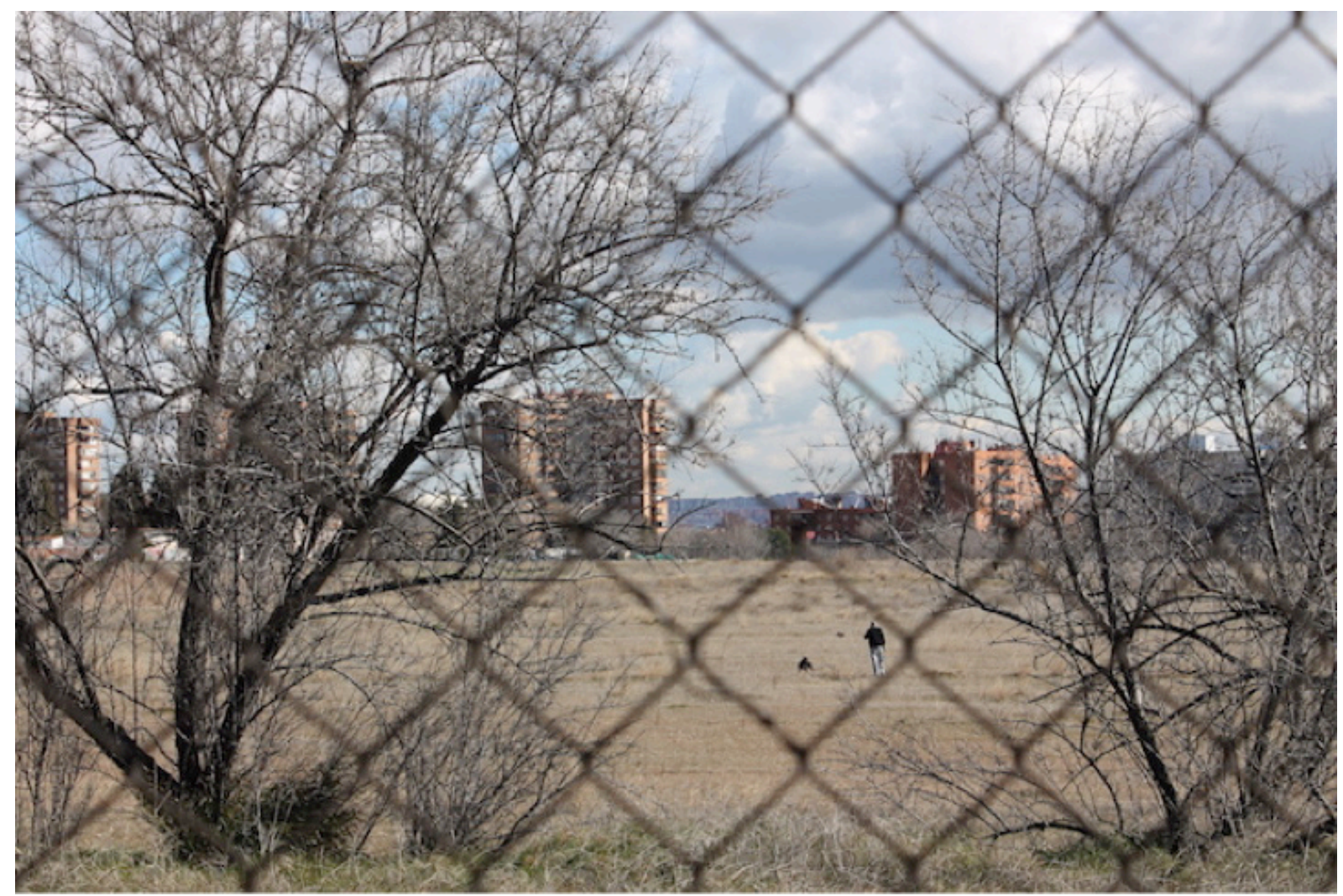

Figura 10: Usos actuales del solar de la cárcel.

Fuente: Autor.

El conflicto entre la planificación institucional y los planteamientos del movimiento vecinal se expresaba a través de diferentes prácticas que hacían tangibles formas distintas de entender los terrenos de la Cárcel de Carabanchel y, en el caso de los vecinos, daban a la vida cotidiana una dimensión material ${ }^{52}$. De esta manera, entraban en pugna distintas ideas y memorias por la resignificación de la cárcel. Lo que entraba en juego, en última estancia, eran distintas formas de pensar la ciudad

50 Expresiones utilizadas por varios informantes durante el trabajo de campo de la investigación.

51 Ortiz 2013.

52 Hiernaux 2004, p.16; Soja 1996, p.74. 
y la planificación urbana ${ }^{53}$. Los vecinos impugnaban la visión gubernamental sobre el futuro de los terrenos a través de una serie de prácticas como eran las concentraciones, las manifestaciones, la irrupción en los terrenos de la cárcel, las visitas al interior,... Y al mismo tiempo, impugnaban el discurso memorial sobre la misma, que buscaba su eliminación, a través de la puesta en práctica de una labor de homenaje y recuperación de la memoria de la represión y de la resistencia antifranquista. Estas acciones de impugnación suponían la expresión de ese espacio vivido dando lugar a diferentes prácticas articuladas en torno a cada uno de los ejes. Por ejemplo la idea de una memoria municipal previa se expresaba con la señalización de los lugares de memoria populares; la cotidianidad de un barrio fordista con un déficit de equipamientos, con las manifestaciones y concentraciones por conseguir estos servicios; y el estigma carcelario, con la irrupción dentro de la cárcel, la aparición de un significado de la misma como patrimonio positivo y la recuperación de la memoria colectiva de la represión a través de prácticas de homenaje como los murales y el 'Jardín de la Memoria'.

Estas prácticas, unidas al discurso de apropiación simbólica de la Cárcel como lugar 'carabanchelero', convirtieron a la prisión, y a sus terrenos, en un lugar convocante llegando incluso a ser un espacio de protesta recurrente en el barrio con las reclamaciones por el hospital, con los homenajes anuales por el derribo y con, incluso, la aparición de un huerto urbano creado por la asamblea del 15M de Carabanchel.

Estas prácticas mantuvieron el solar como un espacio en disputa que rompía la dinámica de verlo como un espacio abandonado y permitieron la presencia del solar como un lugar reclamado. Por lo tanto, estas acciones continuadas se convirtieron en acciones políticas y en prácticas de testimonio ${ }^{54}$.

Esta apropiación del solar lo ha convertido en un espacio en uso en la actualidad. Parte del solar es un depósito de vehículos incautados por la policía, están los restos del huerto urbano, algunos inmigrantes realizan prácticas deportivas en uno de los laterales del recinto, también están los memoriales populares donde destaca el 'Jardín de la Memoria', algunos vecinos pasean con sus mascotas por el solar, lo atraviesan, se realizan actividades informales como el intercambio y recogida de materiales y algunas personas sin hogar viven dentro del mismo al lado de unos restos de muro perimetral de la prisión que todavía sigue en pie.

\section{Conclusiones}

La investigación de la que derivaba este artículo tenía el objetivo último de aportar un análisis que permitiera establecer una relación entre espacio y memoria que superara las formas tradicionales en la que estas ideas se habían venido relacionando de manera incipiente hasta la fecha. Se buscaba, con el análisis del caso de estudio, superar los abordajes que reducían esta relación a aproximaciones históricas, artísticas y patrimoniales. A juicio de la investigación, la producción del espacio de

53 Till 2012, p.4.

54 Till 2012, p.4. 
Lefebvre ${ }^{55}$, producto y productora de las relaciones de poder, marcaba el conflicto entre las memorias fuertes y las memorias débiles ${ }^{56}$, es decir, entre las oficiales/hegemónicas y las subalternas/contrahegemónicas.

De esta manera, y siguiendo la relación que acabamos de señalar, en el caso de la Cárcel de Carabanchel, la concepción del espacio tras su derribo actuaba como una verdadera política de memoria que tenía como objetivo último la eliminación de un lugar vinculado a la represión, es decir, a un relato del pasado que resultaba conflictivo, para pacificar el espacio destinándolo a la residencia, el tránsito y el consumo dentro de la línea discursiva de la memoria 'buena' que presidía el relato del consenso transicional. Esta representación del espacio establecía una continuidad de la trama urbana en base a unos criterios previos dentro de los cuales la recuperación de esa memoria subalterna y la representación de los significados vecinales derivados de la vivencia diaria del espacio no se tenían en cuenta. Así, el proyecto urbano, mediante la eliminación material de la prisión y la planificación posterior que contemplaba, despreciaba los significados que la cárcel tenía para la identidad barrial, la conversión de la misma en un espacio apropiado por los vecinos como un lugar convocante y la memoria antifranquista que portaban los ex presos.

Esta concepción entraba en conflicto con una espacio vivido donde la cárcel aparecía como un lugar emblemático vinculado a los ejes que articulaban la identidad 'carabanchelera', a saber, la memoria de una existencia municipal previa donde la prisión había sido un elemento característico de la evolución urbana y demográfica de la zona; la experiencia cotidiana de un barrio de origen fordista marcado por las desigualdades infraestructurales y la falta de equipamientos 'positivos'; y, por último, el estigma carcelario y de peligrosidad construido desde el exterior y fuertemente vinculado a la presencia de la prisión. La forma de positivizar ese discurso se articuló en torno a la recuperación de la memoria de la cárcel vinculada a la resistencia antifranquista y a su conversión en patrimonio de Carabanchel a destacar, conservar y potenciar. Así, esta forma de vivir el espacio cargado de significados y simbolismos propios se oponía al proyecto institucional que no sólo planificaba un espacio homogéneo que reducía la zona al carácter residencial, de consumo y mantenía las connotaciones negativas sin elementos positivos a destacar, sino que también pacificaba una memoria que resultaba incomoda y que el movimiento social formado por vecinos y ex presos consideraba contrahegemónica.

En el artículo se ha podido apreciar cómo la prisión pasó de ser un lugar reclamado por su uso, puesto que se pretendía la ubicación en sus terrenos de equipamientos sociales que se consideraban necesarios desde un espacio vivido articulado sobre esa identidad de barrio fordista desigualmente tratado, a ser un lugar reivindicado por lo que significaba y simbolizaba como un patrimonio propio del barrio desde una visión positivizada del mismo derivada de su conversión en un lugar

55 Lefebvre 2013 [1974].

56 Traverso 2007. 
ocupado y apropiado y que, a su vez, permitía la recuperación de una memoria que el relato hegemónico del pasado pretendía borrar.

Tanto concepción como vivencia aparecían de esta manera en el análisis como elementos irreconciliables en cuanto a la Cárcel de Carabanchel. Así, este lugar permitía hacer empíricamente observable el conflicto inherente a la producción del espacio que atravesaba el enfrentamiento entre relatos del pasado que aparecían como contrapuestos. Las distintas ideas en disputa se hacían tangibles a través de prácticas espaciales como eran las políticas públicas sobre la prisión, su demolición, las manifestaciones, el abandono institucionales durante una década, las concentraciones, las ocupaciones y la construcción de memoriales. Prácticas que hacían visibles estos conflictos interrelacionados.

En definitiva, analizar el proceso de lucha por mantener la Cárcel de Carabanchel, ha permitido constatar cómo los proyectos institucionales, la concepción del espacio, no sólo buscan determinar de manera normativa la forma en la que los grupos viven y usan el espacio público sino que también establecen los discursos hegemónicos y oficiales sobre el pasado que pueden completar la función de representación identitaria y de transmisión intergeneracional. De manera opuesta, el espacio vivido expresa, a través de sus significados, símbolos y lugares afectivos, formas alternativas de entender y usar el espacio público, a la vez que portan memorias sociales subalternas que tratan de impugnar o sustituir esas memorias oficiales a través de prácticas concretas. Por lo tanto, considerar la forma en la que se produce el espacio es un elemento esencial a la hora de analizar cómo los relatos del pasado entran en conflicto y exponen significados diferentes sobre ciertos lugares.

\section{Bibliografía}

AZARYAHU, Maoz. RePlacing Memory: the reorientation of Buchenwald. Cultural geographies, 2003, no 10, p. 1-20.

BLEE, Kathleen y TAYLOR, Verta. Semi-structured interviewing in Social Movement Research. In KLANDERMANS, B. y STAGGENBORG, S. Methods of social movement research. Minneapolis: University of Minesota Press, 2002, p. 92-117.

CAIRO CAROU, Heriberto. The field of Mars: heterotopias of territory and War. Political Geography, 2004, Vol. 23 nº, p. 1009-1036.

COMPAÑY, Gonzálo y BIASATTI, Soledad. ¿Dilución o dilucidación? Usos y usos en torno a las topografías del terror. EBRE 38, 2011 , nº 6, p. 203-221.

CRESSWELL, Tim. Place, a short introduction, Oxford: Blackwell Publishing, 2004.

FOOTE, Kenneth. Shadowed Ground. America's Landscapes of Violence and Tragedy. Austin (Texas): University of Texas Press, 1997.

FOOTE, Kenneth y AZARYAHU, Maoz. Toward a Geography of memory: geographical dimensions of public memory and conmmemoration. Journal of Political and Military Sociology, 2007, Vol. 35 nº 1, p. 125-144.

FOUCAULT, Michel. Of other spaces: utopias and heterotopias. Architecture/ Mouvement/ Continuité, 1986, n 5, p. 1-9. 
FULLILOVE, Mindi. Root shock: How tearing up city neighborhoods hurts America, and what we can do about it. New York: One World/Ballatine Press, 2004.

GARCÍA GARCÍA, Sergio. Seguridad e identidad en Carabanchel. Los significados de un barrio como herramienta para el Trabajo Social. Cuadernos de Trabajo Social, 2008, n² 28, p. 63-85.

GARCÍA GARCÍA, Sergio. Cuando éramos malos...el estigma penitenciario en Carabanchel. In ORTÍZ GARCÍA, Carmen. Lugares de represión, paisajes de la memoria. La Cárcel de Carabanchel. Madrid: Los libros de Catarata, 2013, p. 141161.

HIERNAUX-NICOLAS, Daniel. Henri Lefebvre: del espacio absoluto al espacio diferencial. Revista Veredas, 2004, n8, p. 11-25.

HITE, Katherine. Politica y arte de la conmemoración. Memoriales en América Latina y España. Santiago de Chile: Mandrágora, 2013.

JELIN, Elizabeth y LANGLAND, Victoria. Introducción. Las marcas territoriales como nexo entre pasado y presente. In JELIN, Elizabeth, y LANGLAND, Victoria. Monumentos, memoriales y marcas territoriales. Madrid: Siglo XXI, 2003, p. 1-18.

JOHNSTON, Ron, GREGORY, Derek, et al. Diccionario AKAL de Geografía Humana. Madrid: Akal, 2000.

JOHNSTON, Ron, GREGORY, Derek, et al. The Dictionary of Human Geography. West Sussex: Blackwell Publishing, 2009.

KARACAS, Cary. Place, public memory, and the Tokyo Air Raid. The Geographical Review, 2010, no 4, p. 521-537.

LEFEBVRE, Henri. La producción del espacio. Madrid: Capitán Swing Libros, 2013 [1974].

MARTÍNEZ GUTIÉRREZ, Emilio. Ciudad, espacio y cotidianidad en el pensamiento de Henri Lefebvre. In LEFEBVRE, Henri. La producción del espacio. Madrid: Capitán Swing Libros, 2013, p. 31-50.

MARTÍNEZ LOREA, Ion. Prólogo. Henri Lefebvre y los espacios de lo Posible. In LEFEBVRE, Henri. La producción del espacio. Madrid: Capitán Swing Libros, 2013, p. 9-28.

MARTÍNEZ I MUNTADA, Ricard. Movimiento vecinal, antifranquismo y Anticapitalismo. Historia, Trabajo y Sociedad, 201 1, n² 2, p. 63-90

MASSEY, Doreen. Politics and Space/Time. In KEITH, Michael y PILE, Steven. Place and the politics of identity. London/New York: Routledge, 1993, p.139-159.

MORENO JIMÉNEZ, Antonio. Carabanchel. Recuperar el espacio vivido. Madrid: Junta Municipal de Carabanchel, 1983.

MITCHELL, Katherine. Monuments, memorials and the politics of memory. Urban Geography, 2003, Vol. 24 (5), p.442-459.

MESKELL, Lynn. Negative heritage and past mastering. Archaeology. Anthropological Quarterly, 2002, Vol.75, n³, p. 557-574.

NORA, Pierre. La aventura de Les lieux de mémoire. Ayer, 1998, nº 32, p. 18-34. 
ORTIZ GARCÍA, Carmen. Avenida de los Poblados sin número. La cárcel de Carabanchel como heterotopía. In OLIVER OLMO, Pedro y URDA LOZANO, Jesús Carlos. La prisión y las instituciones punitivas en la investigación histórica. Ciudad Real: Universidad de Castilla-La Mancha, 2013, p. 453-473.

ORTÍZ GARCÍA, Carmen. Patrimonio sin monumentos. Políticas de la memoria y gestión patrimonial de los sitios de represión del franquismo. El caso de la Cárcel de Carabanchel. In ORTÍZ GARCÍA, Carmen. Lugares de represión, paisajes de la memoria. La Cárcel de Carabanchel. Madrid: Los libros de Catarata, 2013, p.42-78

OVIEDO SILVA, Daniel. Paisaje urbano y mapa de la represión: Carabanchel Bajo. 1939-1945. In ORTÍZ GARCÍA, Carmen. Lugares de represión, paisajes de la memoria. La Cárcel de Carabanchel. Madrid: Los libros de Catarata, 2013, p.162185.

RODRÍGUEZ LESTEGÁS, Francisco. La estrategia socioespacial de las heterotopías: ¿el poder organiza espacios de exclusión o de fijación?. Xeográfica. Revista de Xeografía, Territorio e Medio Ambiente, 2006, nº 6, p. 171-179.

RODRIGO SÁNCHEZ, Javier. Los campos de concentración franquistas. Entre la Historia y la Memoria. Madrid: Siete Mares, 2003.

SÁNCHEZ-CARRETERO, Cristina. Patrimonialización de espacios represivos: en torno a la gestión de los patrimonios incómodos en España. In ORTÍZ GARCÍA, Lugares de represión, paisajes de la memoria. La cárcel de Carabanchel. Madrid: Los libros de Catarata, 2013, p. 28-41.

SÁNCHEZ MOLLEDO, Jose María. Carabanchel: un distrito con historia. Madrid: Ediciones La Librería, 2011.

SCHMID, Christian. Henri's Lefebvre theory of the production of space. Towards a three-dimensional dialectic. In GOONEWARDENA, Kanishka, KIPFER, Stefan, MILGROM, Richard. et al. Space, difference, everyday life. Reading Henri Lefebvre New York: Routledge, 2008, p.27-45

SEQUERA FERNÁNDEZ, Jorge. Del movimiento vecinal a las movilizaciones por una vivienda digna. De la necesidad hecha derecho al derecho hecho necesidad. Nómada. Revista Crítica de Ciencias Sociales y Jurídicas, 201 1, Vol. 29, nº 1, p. 1-16 SOJA, Edward. Thirdspace. Journeys to Los Angeles and other real and imagined places. Malden (Massachusetts): Blackwell Publishers Inc., 1996.

SOJA, Edward. Postmetrópolis: Estudios críticos sobre las ciudades y las regiones. Madrid: Traficantes de Sueños, 2008.

SUAREZ, Luis y GALANTE, José. Cárcel de Carabanchel: lo que no ha podido destruir la piqueta. Viento Sur, 2008, no 101, p. 95-100.

TILL, Karen. Emplacing Memory Through the City: the New Berlin. GHI Bulletin, 2004, n³5, p.73-83.

TILL, Karen. Artistic and activist memory-work: Approaching place-based Practice. Memory Studies, 2008, Vol.1 nº1, p. 99-113.

TILL, Karen. Urban remnants: Place, Memory and Artistic practice in Berlin and Bogotá. Encounters, 2010, nº 1, p. 75-87. 
TILL, Karen. Wounded cities: Memory-work and a place-bases ethics of care. Political Geography, 2012, Vol.31 nºl, p. 3-14.

TODOROV, Tzvetan. Los abusos de la memoria, Barcelona, Paidós, 1995.

TRAVERSO, Enzo. El pasado, instrucciones de uso. Historia, memoria, politica. MadridBarcelona: Marcial Pons, 2007.

VINYES, Ricard. El Estado y la Memoria: Gobiernos y ciudadanos frente a los traumas de la historia. Barcelona: RBA Libros, 2009.

WITHERS, Charles. Memory and the history of geographical knowledge: the commemoratión of Mungo Park, African explorer. Journal of Historical Geography, $2004, n^{0} 30$, p. 316-339.

(c) Copyright: Sergio Claudio González García, 2018

(c) Copyright: Scripta Nova, 2018.

Ficha bibliográfica:

GONZÁLEZ GARCÍA, Sergio Claudio. Vecinos recuperando la memoria: la cárcel de Carabanchel. Scripta Nova. Revista Electrónica de Geografía y Ciencias Sociales. Barcelona: Universidad de Barcelona, 1 de octubre de 2018, vol. XXII, nº 599. [ISSN: 1138-9788] 